Non-neoplastic disorders associated with raised $\alpha$ fetoprotein concentrations

Paediatric

Tyrosinaemia

Indian childhood

cirrhosis

Neonatal hepatitis

Adult

Primary biliary cirrhosis

Extrahepatic biliary

obstruction

Alcoholic hepatitis

Chronic active hepatitis

Drug induced hepatitis

Viral hepatitis should lead to a fall in $\alpha$ fetoprotein concentration consistent with its known half life of five days. If this fails to occur chemotherapy resistance is suggested and urgent further investigation is needed, together with a reappraisal of treatment. A rising or persistently raised concentration of $\alpha$ fetoprotein on its own, in the presence of normal results of clinical and radiological investigations, is conventionally indicative of relapse 4 .

Although measurement of $\alpha$ fetoprotein is valuable in the management of germ cell tumours, several situations exist in which raised concentrations of $\alpha$ fetoprotein may not be due to a new or recurrent malignancy (box). The development of a radioimmunoassay for $\alpha$ fetoprotein to replace less sensitive assays that used countercurrent immunoelectrophoresis has led to the observation that serum $\alpha$ fetoprotein concentrations may be marginally raised in some normal healthy people, including a subset of individuals with a familial predisposition, expressed in an autosomal dominant fashion. ${ }^{5}$ Raised $\alpha$ fetoprotein concentrations may be associated with living in certain environments, such as the Ivory Coast and savanna regions of Africa, possibly because of increased exposure to hepatotoxins. ${ }^{6}$

Production of $\alpha$ fetoprotein is also increased in association with hepatic parenchymal inflammation, hepatic necrosis, and hepatic regeneration. The greater the changes the higher the concentration of $\alpha$ fetoprotein, which may reach $300000 \mu \mathrm{g} / \mathrm{l}$ in fulminant hepatic necrosis. In our patient increased production of $\alpha$ fetoprotein was due to alcoholic hepatitis, which subsided only once his alcohol intake was appreciably reduced. Although raised $\alpha$ fetoprotein concentrations secondary to chemotherapy regimens containing methotrexate have been observed, no reports of this effect of methotrexate have been published. $\alpha$ Fetoprotein concentrations are raised as a result of excessive alcohol intake but only in the presence of hepatitis. No correlation has been shown between raised liver enzyme activities and $\alpha$ fetoprotein concentrations without histological changes in the liver.

As this case illustrates, the major problem with using $\alpha$ fetoprotein concentration is its heterogeneity, which causes poor assay sensitivity and specificity. Clearly, identification of the different "species" of $\alpha$ fetoprotein in various benign and malignant conditions would be extremely useful clinically. In our patient the results of such assays would have shown that the failure of his serum $\alpha$ fetoprotein concentration to decline after chemotherapy was due to increased hepatic synthesis of $\alpha$ fetoprotein secondary to alcoholic hepatitis.

$\alpha$ Fetoprotein is a very large protein and has several surface epitopes. ${ }^{7}$ The different molecular forms of $\alpha$ fetoprotein in benign liver disease, hepatoma, germ cell tumours, and hepatic metastases from colorectal neoplasms can be differentiated by their lectin binding properties $^{8}$ or by monoclonal antibodies, which might offer a better prospect of establishing the source of a raised serum $\alpha$ fetoprotein concentration. ${ }^{10}$

The presence of persistently raised concentrations of $\alpha$ fetoprotein after chemotherapy for germ cell tumours necessitates urgent and thorough investigation to exclude residual disease. In a small proportion of patients inappropriately high concentrations may be familial or secondary to hepatic injury. Identification of different species of $\alpha$ fetoprotein in such patients by either the lectin binding ability or the surface epitopes of these species would prove extremely useful and may prevent further, inappropriate treatment being started.

1 Newlands ES, Bagshawe KD, Begent R, Rustin JG, Crawford SM, Holden L. Current optimum management of anaplastic tumours of the testis and other sites. Br 7 Urol 1986;58:307-1

2 Klein EA. Tumor markers in testicular cancer. Urol Clin North $\mathrm{Am}$ 1993;20(1):67-73.

3 Sell S. Cancer markers for the 1990s. Clin Lab Med 1990;10:1-37.

4 Hendry WF. Surgical management of advanced testicular cancer. In: Waxman J, Williams G, eds. Urological oncology. London: Edward Arnold, 1992.

5 Greenberg F, Alpert E, Rose E. Hereditary persistence of alphafetoprotein. Gastroenterology 1990;98:1083-5.

6 Minghetti PP, Harper ME, Alpert E. Chromosomal structure and localization of human alphafetoprotein gene. Ann N Y Acad Sci 1983;417:1-12.

7 Breorowicz J. Microheterogeneity of human alphafetoprotein. Tumour Biol 1988;9:3-14.

8 Buamah P, Cornell C, Cassells-Smith AJ. Differential reactivity of alphafetoprotein with lectins and its usefulness in the diagnosis of various liver diseases. Clin Chim Acta 1987;168:69-73.

9 Buamah P, Cornell C, Skillen AW. Affinity chromotography used in distinguishing alphafetoprotein in serum from patients with tumors of hepatic parenchyma and of germ cells. Clin Chem 1984;30:1257-8.

10 Chakroborty M, Mandal C. Epitope analysis of the oncofetal antigen alphafetoprotein using monoclonal antibodies. Mol Immunol 1991;27:70310.

(Accepted 30 September 1994)

\title{
Cambodian health in transition
}

\author{
Mam Bun Heng, P J Key
}

As conflict and suffering in Bosnia, Chechnya, Rwanda, and Zaire continue to be at the forefront of world attention, some countries seem to be largely forgotten. It is timely to take stock of conditions in the small country of Cambodia as it struggles to take its place after a long period of isolation. Countless Cambodians and ethnic Vietnamese have died there this year and during the past 25 years, victims of senseless killing or preventable disease.

Phnom Penh, Cambodia Mam Bun Heng, under secretary of state for health

Overseas Development

Administration, London SW1E 5JL

P J Key, deputy head, health and population division

Correspondence to: Dr Key.

$B M F$ 1995;311:435-7 are harrowing. Cambodia now has a fast growing population of around 9 million, a fifth of whom are children under 5 years old. Their health and safety are still precarious.

\section{Background}

The past 20 years of Cambodian history have been characterised by civil war and terrible brutality. In the early 1970s the country suffered intense bombing by the United States on its western border with Vietnam. The fall of Phnom Penh to the Khmer Rouge marked the beginning of four years of genocide under the rule of Pol Pot; the country was turned into a "killing field," with up to two million people dying as the result of violence, starvation, and disease. In 1979 the Vietnamese ended Pol Pot's rule and installed a hardline socialist regime. Over the next 10 years Cambodia suffered a vicious civil war as the government in Phnom Penh battled with guerrilla factions backed 


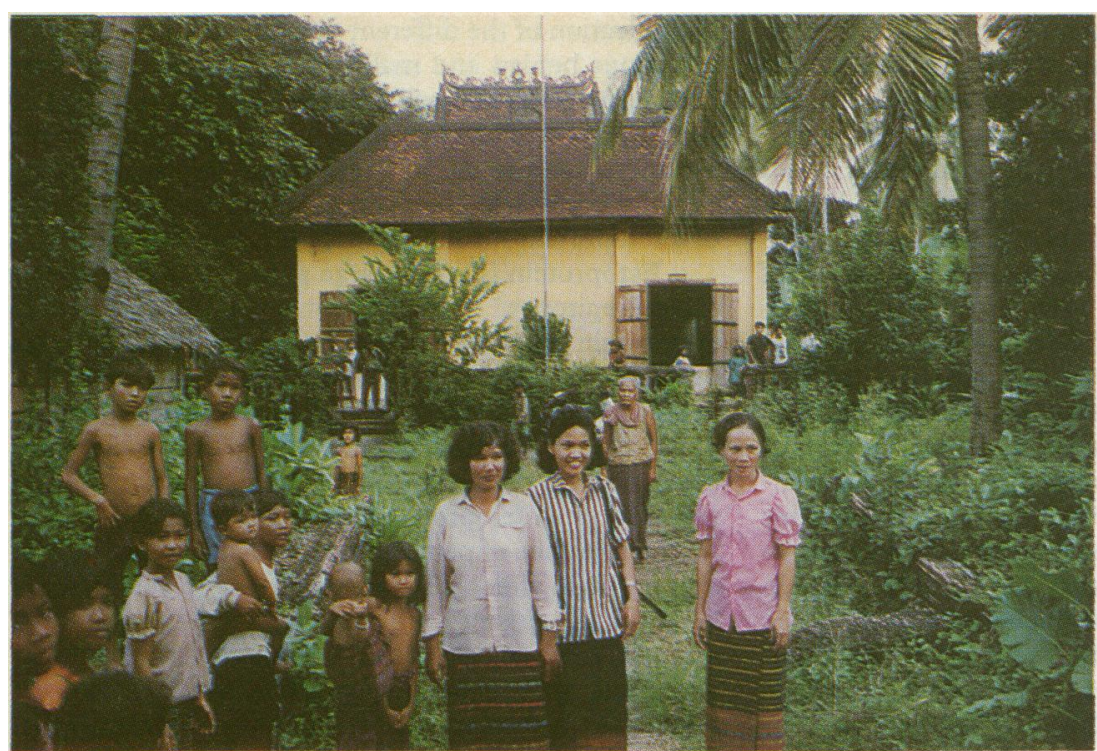

Nurses at a village clinic. There is much to be done before primary care is available to all Cambodians

by the West. The long period of civil disturbance and conflict left many more thousands dead or disabled.

The public health infrastructure was another casualty of these decades of violence. Under Pol Pot the Cambodian professional classes were destroyed to the extent that only 25 doctors and three members of staff at the ministry of health remained. Although the new regime backed by the Vietnamese tried to train large numbers of health workers quickly, the training was not accredited to international standards and its quality was untested and questionable. Other distortions also emerged. Salaries for all government staff were below a living wage, with doctors earning about $\$ 30$ a month in 1992. Low incomes had to be supplemented by private practice, which was most lucrative in towns. Few doctors were prepared to work in rural areas, where health problems were gravest and purchasing power the lowest.

Thus a two tier health service has emerged. On the one hand, is the public sector, which is badly underfunded. Health facilities are in disrepair and without water, electricity, equipment, or drugs; staff are present for only a few hours each day and always try to make patients pay a fee. Thus only a few patients are treated. On the other hand, is the private sector, which is thriving in the towns (usually in private houses), with quality and cost totally unregulated.

\section{Health indicators}

Cambodia has some of the worst health indicators in Asia. Although no firm data are available, the ministry of health estimates that life expectancy is about 47 years for men and 49 years for women, infant mortality 120 per 1000 live births, child mortality 190 per 1000 , and maternal mortality nine per 1000 births. Because many men were killed in the conflicts, there are more women than men of reproductive age, and over a fifth of households are headed by a woman.

Many of the diseases that kill Cambodians are not new to developing countries. In infants and children these are tetanus, diarrhoeal diseases, acute respiratory infections, haemorrhagic dengue, and diseases that can be prevented by vaccination. Women of reproductive age have complications of pregnancy, abortion, and delivery, often superimposed on severe anaemia, undernutrition, and malaria. What makes Cambodia different is the scale and complexity of these diseases. For instance, diarrhoea is also a major cause of serious illness in adults, and typhoid and cholera are endemic because access to clean drinking water and latrines is extremely limited everywhere (even in the capital). Then there are the major killers: malaria and tuberculosis.
Cambodian malaria is among the most intransigent and deadly in the world. Malaria (primarily Plasmodium falciparum) is the single greatest cause of illness and death, with an estimated half a million cases each year and between 5000 and 10000 deaths. About a fifth of maternal deaths are attributed to malaria. The ministry of health estimates that up to a third of all Cambodians are at serious risk of malaria. The remote forested areas, where health services are weakest and security is poorest, are the worst affected. Recent mass movements of people, poor compliance with drug regimens, and unregulated dispensing of antimalarial drugs in the private sector have contributed to drug resistance that is regarded by the World Health Organisation as among the most serious in the world.

The annual incidence of pulmonary tuberculosis is estimated to be 250 per 100000 people. This means that every year 40000 new cases are expected, of which 20000 will have sputum that is positive for Mycobacterium tuberculosis. Of these 40000 new cases each year, an estimated 11000 will be treated but only 4400 of affected patients will complete the full course. Shortage of drugs, failure to complete the course of treatment, inadequacy of the 12 month protocol, and growing drug resistance limit the effectiveness of the national tuberculosis control programme.

The rapid spread of HIV infection in South East Asia poses a formidable challenge to Cambodia. Neighbouring Thailand has one of the highest infection rates in the world, and the prevalence is increasing in Vietnam. Cambodia is likewise showing all the signs of an exponential rise in HIV infection rates. Recent sample surveys show that the prevalence of HIV infection is over $50 \%$ in commercial sex workers in some areas, and about $10 \%$ in the police and armed forces. Blood donors testing HIV positive have increased from under $1 \%$ in the early 1990 s to $4 \%$ in 1994. The presence of a large United Nations peace keeping force from early 1992 to the end of 1993 and the easing of the political and economic situation have brought in their wake a fast growing commercial sex industry. The large shifts in population for political and economic reasons, returning refugees, and the porous borders with neighbouring countries have also bolstered HIV transmission.

The history of violence has left a legacy unique to Cambodia: large numbers of disabled people and about 13 million land mines in a land of 9 million people. There are about 20000 people with amputations in the country; each month between 100 and 200 people have a limb amputated and a further 200 or so die of injuries caused by land mines. Local manufacturing capacity for prostheses is limited, and in any case artificial limbs are a valuable resaleable commodity among the poor. As with HIV infection, the young adult population working in fields or forests is at greatest risk of injury.

The Cambodian ministry of health recognises and is much concerned that highly traumatising events such as the prolonged war, the dislocation of families and loss of relatives, and the constant fear of injury from mines have resulted in considerable psychiatric morbidity, with many people in need of psychiatric and counselling services. Studies among displaced Cambodians in border camps show an unusually high incidence of mental ill health. Overstretched resources and limited qualified staff mean, however, that mental health care services are not currently provided and that psychiatry and psychology are not part of the current educational curriculum for health professionals.

\section{The future}

The violence continues. But the Cambodians are trying to re-establish the public health care services, 
which were almost totally dismantled. This is a priority for national leaders. The signing of the Paris Peace Accord in 1991 ended political isolation and allowed international donors to expand humanitarian initiatives. With the combined efforts of the national government and national and international organisations, particularly non-governmental organisations, parts of the health service have been revitalised rapidly and the transitional phase leading to long term development has begun.

The new royal Cambodian government, with much help from WHO technical experts, has taken important steps to re-establish a viable health care system. With its decimated health care workforce, low level of recurrent finance for health care, and limited managerial capacity, Cambodia has moved rapidly to establish sensible health policies and plans, mechanisms to coordinate external donors, and options to increase the finance available for health care and to improve the use of existing non-governmental health practitioners. The Cambodian ministry of health is one of the first in the world to lead the way for more widespread civil service reform, starting with changes in budget and accounting practice and moving into human resource planning and management. Senior health managers, working closely with the WHO and Unicef, have already earned the respect of professionals in the World Bank, Asian Development Bank, United Nations Development Programme, and major bilateral agencies, all of which are optimistic that Cambodia is pulling through and that there is a reasonable prospect within the next 10 years of establishing an appropriate and sustainable health system, suited to and meeting the needs of the Cambodian people.

There is, however, much more to be done before even a minimum package of primary health care activities is available to all Cambodians. Health services need to aim for reduced financial and technical dependence on external donors and for long term sustainability. This means devising alternative, indigenous methods of financing health services. Although foreign technical skills are available in abundance in Cambodia, what Cambodian health professionals need most now is to see for themselves how other countries in the region have tackled similar problems, and to learn from their experiences. The goals of Cambodia's national health development plan for 1994-6 are, by its own admission, ambitious, but they need to be because "the health needs of [the Cambodian] people are so great."

\section{Obesity in Britain: gluttony or sloth?}

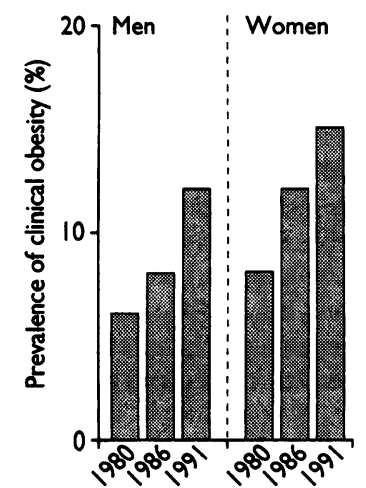

FIG 1-Prevalence of clinical obesity (body mass index $>30$ ) in England. Source: Office of Population Censuses and Surveys ${ }^{1-3}$

\section{MRC Dunn Clinical Nutrition Centre,} Cambridge CB2 2DH Andrew M Prentice, head of energy metabolism group Susan A Jebb, research scientist

Correspondence to: Dr Prentice.

BMF 1995;311:437-9

\section{Andrew M Prentice, Susan A Jebb}

The prevalence of clinical obesity in Britain has doubled in the past decade. The Health of the Nation initiative has set ambitious targets for reversing the trend in recognition of the serious health burden which will accrue, but efforts to develop prevention and treatment strategies are handicapped by uncertainty as to the aetiology of the problem. It is generally assumed that ready access to highly palatable foods induces excess consumption and that obesity is caused by simple gluttony. There is evidence that a high fat diet does override normal satiety mechanisms. However, average recorded energy intake in Britain has declined substantially as obesity rates have escalated. The implication is that levels of physical activity, and hence energy needs, have declined even faster. Evidence suggests that modern inactive lifestyles are at least as important as diet in the aetiology of obesity and possibly represent the dominant factor.

\section{The size of the problem}

Department of Health statistics show that the prevalence of serious obesity doubled in Britain between 1980 and 1991 (fig 1) and is continuing to increase. ${ }^{4}$ In the United States, latest survey data show that obesity is much more prevalent than in Britain and is still increasing; in certain ethnic and regional subgroups $50 \%$ of women are clinically obese. ${ }^{5}$ The American experience provides no grounds for optimism regarding the developing epidemic in Britain.

Obesity is one of the most important avoidable risk factors for a number of life threatening diseases and for serious morbidity. ${ }^{6}$ In the United States it has been estimated to contribute $8 \%$ of all illness costs (around $£ 40$ billion a year). ${ }^{7}$ For these reasons the Health of the Nation initiative has recognised obesity as a key target and set ambitious goals for substantial reductions by the year 2005 .

Uncertainty over the aetiology of obesity remains one of the chief barriers to designing effective strategies for prevention and treatment. It is certain that obesity develops only when there is a sustained imbalance between the amount of energy consumed by a person and the amount used up in everyday life. But which side of this energy balance equation has been most altered in recent decades to produce such rapid weight gain? Should obesity be blamed on gluttony, sloth, or both? This paper reviews evidence from diverse sources in an attempt to throw light on this debate.

\section{Susceptibility to obesity: metabolic or behavioural?}

Obesity exhibits both genetic and familial associations, suggesting an element of individual susceptibility that interacts with adverse environmental conditions to cause extreme weight gain. There has been a tendency for aetiological research to focus on possible metabolic defects which might explain why particular individuals are unable to regulate energy balance. For instance, in the 1970 s the perception that obese people ate less than their lean counterparts triggered massive research investment into an abortive search for an energy sparing defect-the "Doctor, it's my metabolism" syndrome.

Such investigations have now largely been abandoned since it is clear that obese people tend to provide biased diet records and habitually eat far more than they claim, thus eliminating the initial basis of the hypothesis. ${ }^{89}$ Many similar investigative trails could be cited. This emphasis on research into metabolic susceptibility persists and was exemplified most recently by intense public interest in a genetic cause for obesity following the sequencing of an "obesity gene" from ob/ob mice. ${ }^{10}$

Recent epidemiological trends in obesity indicate, however, that the primary causes of the problem must lie in environmental or behavioural changes affecting large sections of the population, since the escalating rates of obesity are occurring in a relatively constant gene pool and hence against a constant metabolic background. 